12,13

\title{
Серебряные структуры на пороге перколяции, полученные с помощью лазерного отжига
}

\author{
( И.А. Гладских, В.А. Полищук, Т.А. Вартанян \\ Санкт-Петербургский национальный исследовательский университет \\ информационных технологий, механики и оптики, \\ Санкт-Петербург, Россия \\ E-mail: 138020@mail.ru
}

(Поступила в Редакцию 22 июня 2016 г.

В окончательной редакции 27 июля 2016 г.)

\begin{abstract}
Экспериментально исследованы электрические, оптические и структурные свойства серебряных наноструктур на пороге перколяции, полученные из проводящей пленки с помощью лазерной обработки. Обнаружено, что при подаче на пленку порогового напряжения резко изменяется ее сопротивление. При высоких напряжениях наблюдается участок с отрицательным дифференциальным сопротивлением. Данные изменения проводимости под действием приложенного напряжения объясняются малыми структурными изменениями пленки.
\end{abstract}

Работа выполнена в рамках грантов РФФИ (16-32-60028 мол_а_дк, 16-32-00165 мол_а) и Госзадания № 2014/190.

DOI: 10.21883/FTT.2017.03.44174.252

\section{1. Введение}

Электрические свойства металлических пленок исследуются довольно долго и представляют несомненный интерес для применения в микроэлектронике. Так, проводимость пленок, состоящих из отдельных наночастиц, очень мала и определяется расстоянием между частицами и материалом подложки. При переходе к перколяционным структурам проводимость резко возрастает и становится близкой к проводимости объемного металла. Электрические свойства металлических структур на пороге перколяции находятся в промежуточной области, причем проводимостью таких структур можно управлять, переключаясь между высокоомным и проводящим состоянием с помощью подаваемого напряжения. Подобные управляемые изменения проводимости обнаружены и активно исследуются во многих материалах [1-4] для использования их в качестве запоминающих устройств.

Наночастицы благородных металлов обладают также уникальными оптическими свойствами, связанными с возбуждением локализованных поверхностных плазмонов. Резонансное электромагнитное излучение значительно усиливается и локализуется вблизи наночастиц, что активно используется для усиления оптического отклика от предельно малого количества вещества (спектроскопия одиночных молекул, ГКР) [5-6]. В металлических пленках, находящихся вблизи порога перколяции и обладающих плазмонными свойствами, усиление падающего поля может достигать $10^{6}$ [7-8].

Получение металлических структур на пороге перколяции при осаждении паров металла в вакууме на подложку невозможно по нескольким причинам. Во-первых, сопротивление пленки в процессе напыления плавно уменьшается, и перколяционный переход при этом прак- тически не заметен [9]. Во-вторых, получаемые структуры неравновесны и продолжают изменяться после окончания напыления, что приводит к большим трудно контролируемым изменениям проводимости пленки [10].

Ранее нами был предложен способ получения структур на пороге перколяции с помощью термической обработки пленок, напыленных до такой толщины, при которой они становятся проводящими. Нагрев проводящих пленок ускоряет диффузию атомов, образующих поверхностную наноструктуру, ведет к формированию отдельных частиц и разрыву соединяющих их перемычек [11-13]. При этом в зависимости сопротивления пленки от времени отжига наблюдается отчетливый переход пленки от проводящей структуры к высокоомной в виде резкого уменьшения проводимости пленки. К недостаткам этого способа получения металлических пленок на пороге перколляции относится именно резкость указанного перехода, так как в силу тепловой инерции быстро прекратить нагрев невозможно.

Значительно большей управляемостью обладает новый способ получения металлических пленок на пороге перколяции, описанный в настоящей работе. Как известно, под действием импульсного лазерного облучения с плотностью энергии в десятки миллиджоулей на квадратный сантиметр серебряные наночастицы нагреваются настолько сильно, что изменяют свою форму [14]. Основное преимущество лазерного отжига по сравнению с термическим состоит в том, что отдельные лазерные импульсы производят относительно небольшие изменения пленки, и перколяционный переход может быть определен более точно.

Важное отличие лазерного отжига от термического заключается в селективном воздействии лазерного излучения на частицы, у которых плазмонная полоса 
поглощения близка к длине волны лазерного излучения. При достаточной энергии излучения частицы изменяют свою форму, что приводит к смещению плазмонного резонанса. Поэтому при таком методе можно точно подстраивать оптические свойства пленки, изменяя длину волны излучения, что невозможно при термическом отжиге, когда нагреваются все частицы в пленке. К преимуществам лазерного отжига можно еще отнести возможность практически мгновенно остановить отжиг, т.к. в отличие от термического отжига происходит локальный нагрев пленки, а также возможность облучать необходимый участок пленки. Второе особенно важно, учитывая, что электроды могут оказывать значительное влияние на морфологию пленки [15].

\section{2. Эксперимент и результаты}

На поверхность кварцевой подложки наносились электроды из серебряного клея. Расстояние между электродами $12 \mathrm{~mm}$, а их ширина - $4 \mathrm{~mm}$. Серебряная пленка толщиной $100 \AA$ напылялась в зазор между электродами

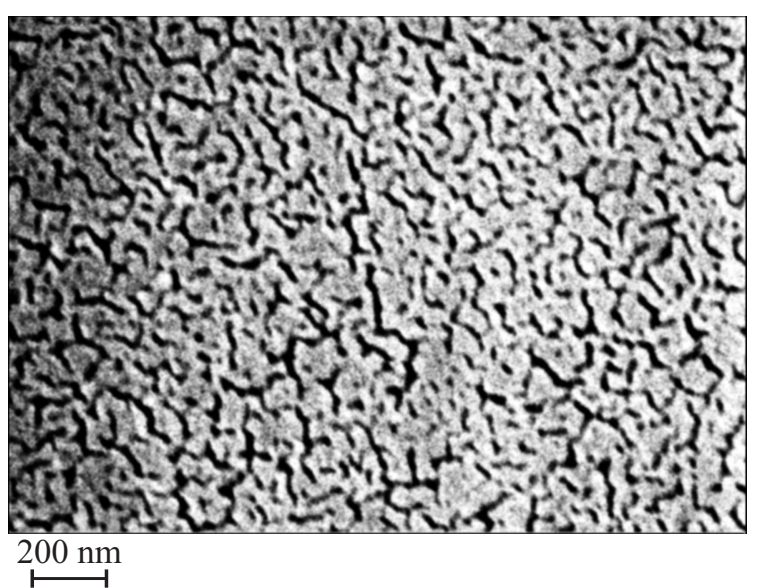

Рис. 1. СЭМ-изображение пленки серебра толщиной $100 \AA$ на поверхности кварцевой подложки.

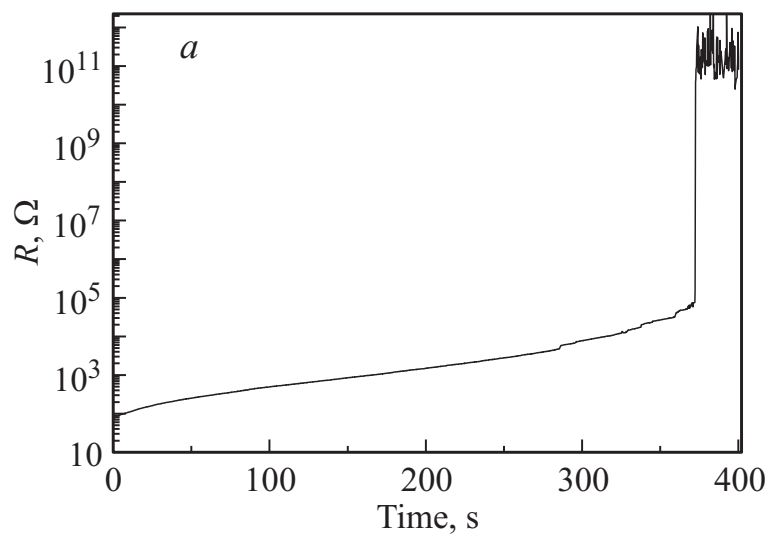

при комнатной температуре подложки в вакуумной установке PVD 75 (Kurt J. Lesker) методом физического осаждения серебра из газовой фазы в вакууме. Скорость напыления контролировалась с помощью кварцевых микровесов и составляла $0.8 \AA / \mathrm{s}$. Как было показано в предыдущих работах, при таких условиях напыления образуются проводящие пленки, имеющие сопротивление от нескольких десятков $\Omega$ до нескольких $k \Omega$. На рис. 1 представлена микрофотография полученной пленки. На ней видна сеть из наночастиц, соединенных между собой и образующих один бесконечный кластер. Основная доля поверхности подложки заполнена серебром с фактором покрытия $f=0.85$. Сопротивление пленки составило $100 \Omega$. Это означает, что между электродами имеется непрерывный металлический путь. В то же время сопротивление значительно больше сопротивления объемного серебра из-за рассеяния электронов на неоднородностях пленки.

Для получения структуры на пороге перколяции пленка облучалась импульсным Nd : YAG-лазером на длине волны $1064 \mathrm{~nm}\left(12.1 \mathrm{~mJ} / \mathrm{cm}^{2}\right)$ и $532 \mathrm{~nm}\left(7.1 \mathrm{~mJ} / \mathrm{cm}^{2}\right)$. Длительность одного импульса - $10 \mathrm{~ns}$, а частота их следования - $10 \mathrm{~Hz}$. Облучение производилось вдали от электродов. Площадь облученного участка пленки составила $16 \mathrm{~mm}^{2}$.

Зависимости сопротивления при напряжении $0.1 \mathrm{~V}$ от времени облучения представлены на рис. 2. Изменение сопротивления при лазерном отжиге аналогично изменению при термическом отжиге [12]. На графике наблюдаются два участка. Первый участок - достаточно плавное увеличение сопротивления от $\sim 100 \Omega$ до $\sim 10^{5} \Omega$ за 370 s и 540 s при облучении первой гармоникой и второй гармоникой соответственно. Рост сопротивления на этом участке вызван утоньшением узких частей наночастиц и уменьшением их количества. Далее наблюдается резкое увеличение сопротивления на 6-8 порядков переход пленки из проводящего состояния в высокоомное, вызванное разрывом всех таких соединений, т.е. структура пленки переходит от бесконечного кластера к отдельным наночастицам. Если остановить облучение

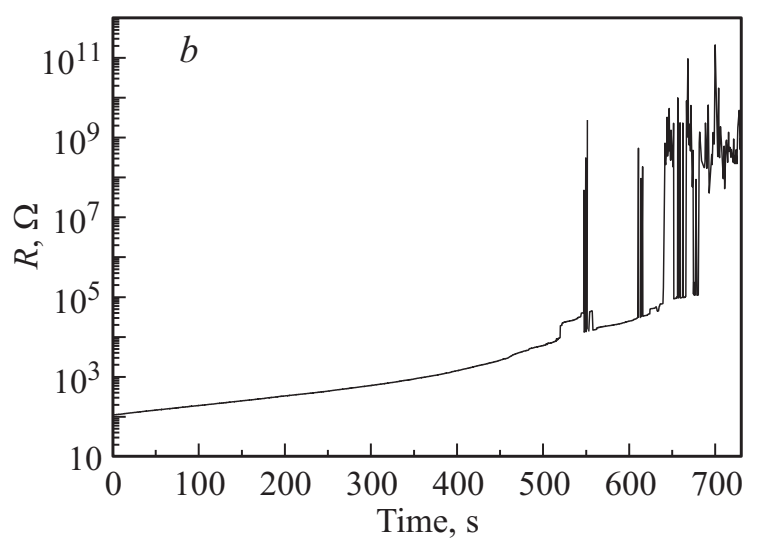

Рис. 2. Зависимость сопротивления пленки серебра на поверхности кварцевой подложки от времени облучения лазером с $\lambda=1064$ (a) и $\lambda=532 \mathrm{~nm}(b)$. 

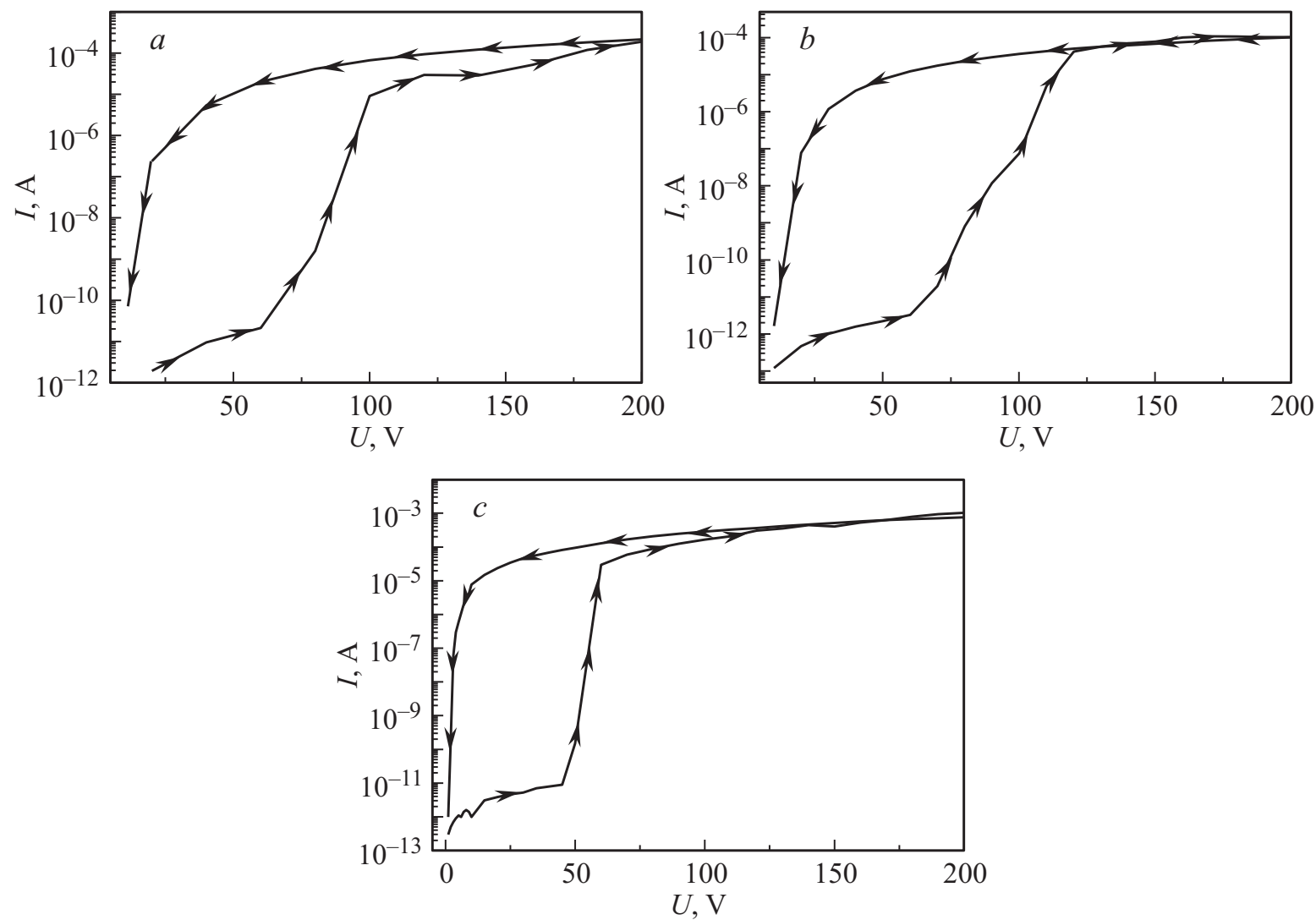

Рис. 3. ВАХ пленок после облучения лазером с $\lambda=1064$ (a) и $\lambda=532 \mathrm{~nm}(b)$ и после термического отжига $(c)$.

практически сразу после этого перехода, то расстояние между частицами будет очень мало.

После облучения измерялись вольт-апмперные характеристики (BAX) пленки (рис. 3). Вне зависимости от длины волны излучения, при которой происходил лазерный отжиг, ВАХ ведут себя практически одинаково. При увеличении напряжения с 0 до $60 \mathrm{~V}$ пленка находится в высокоомном состоянии. В интервале $60-120 \mathrm{~V}$ наблюдается резкое падение сопротивления на 6 порядков. Дальнейшее увеличение напряжения до $200 \mathrm{~V}$ приводило к незначительному падению сопротивления. При уменьшении напряжения сопротивление практически не изменяется вплоть до 20 V. При снятии напряжения пленка переходила обратно в высокоомное состояние. Данная зависимость повторялась многократно с небольшими изменениями порогового напряжения, необходимого для перевода пленки в проводящее состояние.

Аналогичные зависимости ВАХ были получены после термической обработки (рис. 3,c). Характер зависимости практически не отличается от образцов, полученных с помощью лазерного облучения. Переход в проводящее состояние был более резким и происходил при подаче напряжения $60 \mathrm{~V}$, а сопротивление в проводящем состоянии было примерно на порядок меньше.

Следует отметить, что при подаче напряжения более $200 \mathrm{~V}$ ВАХ имела иной характер. На рис. 4 представлена ВАХ в линейном масштабе пленки серебра после облучения лазером на длине волны $532 \mathrm{~nm}$, измеренная в интервале напряжений 0-500 V. При первом проходе при напряжениях более $200 \mathrm{~V}$ рост тока от напряжения значительно замедлился, а при приближении к $500 \mathrm{~V}$ значение тока уменьшается с ростом напряжения, т.е. наблюдается участок с отрицательным дифференциальным сопротивлением. При уменьшении напряжения величина сопротивления соответствовала сопротивлению

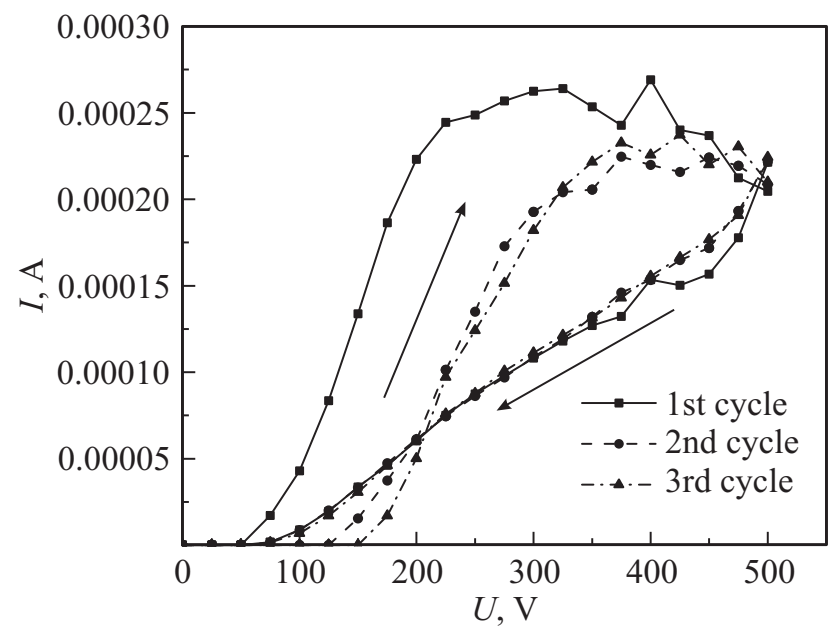

Рис. 4. Серия ВАХ пленок после облучения лазером $\lambda=532 \mathrm{~nm}$. 

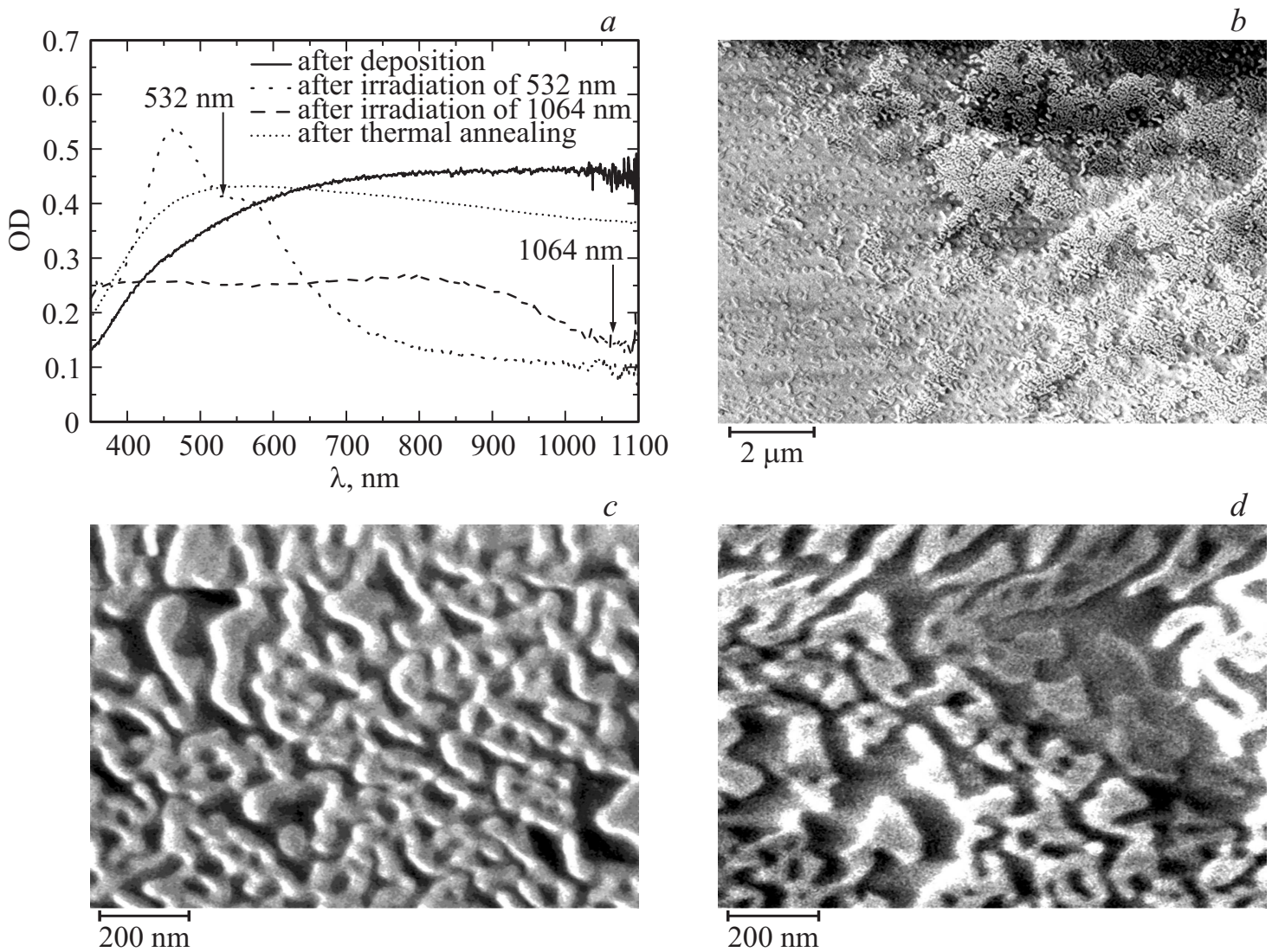

Рис. 5. Спектры оптической плотности $(a)$ пленок после напыления и после лазерной и термической обработки и СЭМ-изображения пленки серебра после облучения лазером с $\lambda=532(b, c)$ и $\lambda=1064 \mathrm{~nm}(d)$.

при максимальном подаваемом напряжении. При последующих измерениях наблюдался рост порогового напряжения, необходимого для переключения сопротивления с $75 \mathrm{~V}$ до $150-175 \mathrm{~V}$.

Таким образом, электрические свойства пленок на пороге перколяции, полученные с помощью лазерного отжига, аналогичны пленкам, исследованным ранее, которые были получены с помощью термической обработки. Также ВАХ слабо отличаются для областей, облученных на длине волны 532 и $1064 \mathrm{~nm}$. А вот спектральные свойства пленок отличаются кардинально. На рис. 5, а представлены спектры оптической плотности пленки серебра после лазерной и термической обработки. Спектр экстинкции пленки до облучения неоднородно уширен из-за ее сложной структуры. При термической обработке наблюдается коротковолновый сдвиг максимума поглощения, обусловленный изменением общей морфологии пленки.

Как уже было сказано, лазерное излучение селективно воздействует на частицы, что вызывает выжигание постоянных спектральных провалов в спектрах оптической плотности. После облучения лазером на длине волны $532 \mathrm{~nm}$ плазмонный резонанс сместился в коротковолновую область. Причем спектр разделен на две части спектральным провалом на длине волны облучения. На рис. 5, $b$ представлено СЭМ-изображение, на котором наблюдаются области, состоящие из крупных отдельных частиц диаметром 100-200 nm, и области, состоящие из лабиринтной структуры. Коротковолновый максимум на длине волны $465 \mathrm{~nm}$ можно связать с возбуждением плазмонного резонанса в круглых частицах. Тогда длинноволновый хвост будет отвечать за поглощение лабиринтной структуры пленки (рис. 5,c).

Лазерное излучение на длине волны $1064 \mathrm{~nm}$ также привело к выжиганию провала в спектре экстинкции пленки. При этом изменении общие изменения были не столь значительные. На СЭМ-изображениях пленки также имеются как лабиринтные структуры (рис. $5, d$ ), так и отдельные частицы (изображение не представлено).

\section{3. Обсуждение результатов}

Лазерный отжиг аналогично термическому приводит к изменению структуры пленки из-за усиленной диффузии атомов под воздействием температуры. Термический отжиг приводит к изменению общей морфологии пленки. При глубоком отжиге в пленках, аналогичных исследуемым в данной работе, в конечном итоге образуются отдельные частицы, форма которых близка к сферической [16]. Для таких частиц плазмонный резонанс расположен около $450 \mathrm{~nm}$. С другой стороны, разрыв 
бесконечного кластера с резким изменением проводимости пленки происходит задолго до образования частиц правильной формы $[11]$, поэтому изменение спектра оптической плотности пленок на пороге перколяции незначительное по сравнению с только что напыленными пленками (рис. 5,a), а их структура по-прежнему остается лабиринтной. Таким образом, при термическом отжиге фактически невозможно получить структуры на пороге перколяции, обладающие разными оптическими свойствами.

При лазерном отжиге нагревается не вся пленка, а лишь частицы с плазмонным резонансом, близким к длине волны лазерного излучения. Такое воздействие приводит к изменению их формы и, как следствие, к выжиганию постоянных спектральных провалов на длине волны излучения. Однако для получения структур на пороге перколяции потребовалась довольно длительная обработка при большой энергии импульсов, что привело к значительному изменению некоторых частей пленки с образованием отдельных наночастиц правильной формы, имеющих плазмонный резонанс в коротковолновой области спектра. Нетрудно предположить, что такой характер проводимости пленки со значительными изменениями сопротивления под действием напряжения будет определяться областями с лабиринтной структурой (рис. 5, с, $d$ ).

Наблюдаемые переключения сопротивления под действием напряжения мы связываем с небольшими структурными изменениями пленки. Размеры металлических наночастиц на СЭМ-изображениях превышают $100 \mathrm{~nm}$. С учетом миллиметровой области облучения и размером частиц образуется порядка $10^{4}$ разрывов. Так как отжиг был остановлен сразу после резкого увеличения сопротивления пленки, то расстояние между наночастицами будет очень мало $(\sim 1 \mathrm{~nm})$. Поэтому, несмотря на относительно небольшое напряжение, подаваемое на пленку, и большое число разрывов, поля в этих местах могут превышать $10^{3} \mathrm{~V} / \mathrm{cm}$, что в свою очередь может приводить к деформации частиц (небольшому вытягиванию) и, как следствие, к их смыканию. Данный процесс лавинообразный, т. к. образование одного мостика между наночастицами приводит к увеличению напряжения на остальных разрывах. В нашем случае процесс образования соединений и новых путей проводимости занимает большой интервал напряжения от 60 до $120 \mathrm{~V}$. После снятия напряжения пленка может опять перейти в высокоомное состояние посредством диффузии атомов с образовавшихся маленьких мостиков на массивные наночастицы. Небольшие отличия ВАХ, полученных при термическом и лазерном отжиге, могут быть связаны с образованием отдельных частиц при лазерной обработке. В таких пленках структурных элементов, отвечающих за проводимость, будет несколько меньше, что и может быть причиной большей величины сопротивления пленки по сравнению с образцом, полученным с помощью термической обработки.

Наблюдаемое насыщение по току и отрицательное дифференциальное сопротивление при большом напря- жении можно объяснить нагревом этих мостиков. Предположительно сопротивление мостиков несколько больше, чем сопротивление массивных наночастиц, поэтому падение напряжения будет преимущественно на них, а следовательно, они будут сильнее нагреваться. При этом сопротивление пленки с ростом напряжения может увеличиваться по двум причинам. Во-первых, сопротивление пленки может увеличиваться при нагреве из-за рассеяния электронов на колебаниях кристаллической решетки. Во-вторых, такое же поведение может быть связано с усиленной диффузией атомов, которая наблюдается при нагреве неотожженных пленок, что ведет к утоньшению мостиков.

В литературе данные о факторе покрытия для порога перколяции сильно разнятся и лежат в диапазоне от 0.4 до $0.78[1,17,18]$. В наших экспериментах для пленки с эквивалентной толщиной $10 \mathrm{~nm}$ фактор покрытия после напыления был 0.85 , что больше указанного диапазона. После облучения фактор покрытия поверхности оказался близок к $0.6-f_{c}=0.61$ и $f_{c}=0.59$ после облучения лазером с $\lambda=1064$ и $\lambda=532 \mathrm{~nm}$ соответственно, хотя при облучении первой гармоникой образуются более крупные частицы.

\section{4. Заключение}

В работе показана возможность получения серебряных наноструктур на пороге перколяции при облучении проводящей пленки мощными лазерными импульсами. В отличие от пленок, полученных при термическом отжиге, после лазерной обработки в спектрах экстинкции пленки наблюдаются провалы на длине волны излучения. Проводимость пленок на пороге перколяции, полученных при лазерном отжиге, была аналогична ранее исследованным пленкам, полученным с помощью термического отжига. Вольт-амперные характеристики пленки после облучения имеют сильную нелинейную зависимость, проявляющуюся в виде резких изменений проводимости пленки под действием приложенного напряжения. При подаваемом напряжении менее $200 \mathrm{~V}$ переключение сопротивления было достаточно стабильно при повторных измерениях, а величина порогового напряжения составила 75 V. При напряжениях более $200 \mathrm{~V}$ наблюдается насыщение по току, а при приближении к $500 \mathrm{~V}$ - участок с отрицательным дифференциальным сопротивлением. Фактор покрытия поверхности для структур на пороге перколяции был близок к 0.6.

Таким образом, лазерный отжиг имеет несомненные преимущества перед термическим для создания плазмонных структур на пороге перколяции, заключающиеся в возможности точной подстройки частоты плазмонного резонанса. В то же время такие структуры благодаря их электрическим свойствам могут применяться при создании устройств памяти, основанных на управляемом изменении проводимости или в качестве ограничителей тока. 


\section{Список литературы}

[1] A. Kiesow, J.E. Morris, C. Radehaus, A. Heilmann. J. Appl. Phys. 94, 6988 (2003).

[2] J.Y. Son, Y.-H. Shin, C.S. Park. Appl. Phys. Lett. 92, 133510 (2008).

[3] D. Tondelier, K. Lmimouni, D. Vuillaume. Appl. Phys. Lett. 85, 5763 (2004).

[4] A. Mehonic, S. Cueff, M. Wojdak, S. Hudziak, O. Jambois, C. Labbé, B. Garrido, R. Rizk, A.J. Kenyon. J. Appl. Phys. 111, 074507 (2012).

[5] J.N. Anker, W.P. Hall, O. Lyandres, N.C. Shah, J. Zhao, R.P. Van Duyne. Nature Mater. 7, 442 (2008)

[6] K.A. Willets, R.P. Van Duyne. Annu. Rev. Phys. Chem. 58, 267 (2007).

[7] A. Otto. J. Raman Spectrosc. 37, 937 (2006).

[8] Z. Wang, L.J. Rothberg. Appl. Phys. B 84, 289 (2006).

[9] S. Wagner, A. Pundt. Phys. Rev. B 78, 155131 (2008).

[10] J. Wu, Z. Wang, K. Wu, J. Zhang, C. Li, D. Yin. Thin Solid Films 295, 315 (1997).

[11] И.А. Гладских, Н.Б. Леонов, С.Г. Пржибельский, Т.А. Вартанян. Оптический журн. 81, 67 (2014).

[12] Т.А. Вартанян, И.А. Гладских, Н.Б. Леонов, С.Г. Пржибельский. ФТТ 56, 783 (2014).

[13] P.V. Gladskikh, I.A. Gladskikh, N.A. Toropov, M.A. Baranov, T.A. Vartanyan. J. Nanopart. Res. 17, 424 (2015).

[14] J. Bosbach, F. Steiz, T. Vartanyan, F. Trager. Appl. Phys. B 73, 391 (2001).

[15] R.D. Fedorovich, A.G. Naumovets, P.M. Tomchuk. Phys. Rep. 328, 73 (2000).

[16] Н.Б. Леонов, И.А. Гладских, В.А. Полищук, Т.А. Вартанян. Оптика и спектроскопия 119, 116 (2015).

[17] K.Y. Yang, K.C. Choi, I.-S. Kang, C.W. Ahn. Optics express 18 , 16379 (2010).

[18] E. Dobierzewska-Mozrzymas, P. Bieganski. Phys. F 18, 2061 (1988). 